\title{
Rheological Behaviors of Bio-degradable Drilling Fluids in Horizontal Drilling of Unconsolidated Coal Seams
}

\author{
Cai Jihua \\ China University of Geosciences, Engineering Faculty, Wuhan, China \\ catchercai@hotmail.com \\ Gu Sui \\ China University of Geosciences, Jiangcheng Faculty, Wuhan, Hubei \\ gusui2006@hotmail.com
}

\begin{abstract}
In China, horizontal drilling techniques have
\end{abstract} been widely used in the exploration of coalbed methane (CBM). The drill-in fluids, especially in unconsolidated coal seams, are typically comprised of cellulose polymers, xanthan polymers and guar gums. However, testing and experience have shown that insufficient degradation of filter cakes resulting from even this "clean" drill-in fluids can significantly impede flow capacity at the wellbore wall. Past approaches to minimizing the damage have been the application of strong acids or oxidative breakers systems. They are often only marginally successful, particularly when applied in extended length intervals. Therefore, this paper introduced an engineered technique incorporating non-toxic, environment friendly and economically attractive bio-degradable drilling fluids (BDF).

Extensive lab tests were conducted to evaluate the effects of substrate (polymer) type, substrate concentration, enzyme type and enzyme concentration on the viscosity breaking behaviors of BDFs. We got the conclusions as follows. (1) Power Law model was the best model to matching the rheological properties of BDFs; (2) Compared with konjak, the degradations of Na-CMC and guar gum were easier to be controlled; (3) In the degradation of CMC by enzyme SE-1, the optimal weight concentration ratio of CMC to SE-1 was 3 to 1; (4) Of the three enzymes, enzyme SE-2 had the highest activity and could be used to degrade polymer in shorter time; (5) Higher enzyme concentration could speed up the degradation reaction; (6) Viscosity breaking times fluctuating from 13.5 hours to 74.5 hours and viscosity breaking ratios varying from $20 \%$ to $100 \%$ could be achieved by modifying the formulations of BDFs.

Index terms - bio-degradable drilling fluid, coalbed methane, rheological, unconsolidated coal seam, enzyme

\section{INTRODUCTION}

In China, practices of horizontal or highly deviated wells, as well as multilateral completions, have developed rapidly in recent years in the exploration of coal bed methane (CBM). The purposes of these activities are to contact more hydrocarbon-bearing payzone area with a single well in order to maximize productivity. Such wellbores often penetrate hundreds of meters of productive zone as opposed to tens of meters contacted in vertical well configurations.

Furthermore, the development of horizontal drilling technologies has been complimented by parallel development of drill-in fluids. The drill-in fluids are formulated to provide the functionality of drilling muds to drill through the productive zone while minimizing the associated wellbore damage experienced with conventional drilling fluids. The standard practice is to drill to the tops of the payzone using the conventional muds and then switches to the cleaner drill-in fluids to drill through the pay [1].

The drill-in fluids, especially in unconsolidated coal seams, are typically comprised of polymers such as starch, cellulose, guar or xanthan. The starch, cellulose and guar provide viscosity for borehole maintaining, friction reduction and lubrication while xanthan polymer 
enhances cutting transport capabilities. Although drill-in fluids are inherently less damaging than the conventional drilling muds, relatively impermeable filter cakes are nonetheless still deposited on the borehole wall. Insufficient degradation of the filter-cakes resulting from even these "clean" drill-in fluids can significantly impede flow capacity at the wellbore wall [2]. This reduced flow capacity can result in significant reduction of the well productivity or injectivity. Formation damage from drilling fluids leaking off into the formation, especially in unconsolidated and high permeability coal seams, as well as filter-cake impairment, must be eliminated to realize the full potential of horizontal completions.

A common approach to minimizing damage during the drilling of openhole horizontal wells is to use a brine-based drill-in fluid system with acid or water-soluble weighting agents followed by the application of acid or an oxidative breaker system to dissolve filter-cake solids and polymers [3-6]. The typical wellbore treatment to remove damage due to the drill-in fluid filter cake consists of pumping $0.497 \mathrm{~m}^{3}$ of $15 \mathrm{wt} \%$ hydrochloric acid per meter of interval [7].

Acids and oxidative solution washes appear to perform reasonably well in the laboratory environment where contact of the filter-cake damage with the reactive solution is easily achieved. However, previous testing had indicated that application of acids or oxidative solutions may not be effective for removing the damage in horizontal intervals [8]. The problem is particularly evident when such treatments are applied in extended length openhole intervals. The primary problem is thought to be inadequate contact of the reactive solution with the drill-in fluid damage [7].

The main deficiency of acids and oxidizers is that they are non-specific reactive species which will react with anything encountered which is oxidizable including tubular goods, hydrocarbons, and some formation components. They are a least partially spent prior to arrival at the damaged location for the non-specific reactants begin spending upon with any oxidizable material. In the situation of extended length openhole intervals, this phenomenon can pose extreme difficulties. Acids also tend to produce wormholes resulting in the generation of additional non-productive reaction area to divert the reactive solution away from the targeted damage [2]. In addition, work has indicated that the polymers often coat the solid particles such as the calcium carbonate. This polymer coating limiting the penetration of acid to the solid and restricts their reaction [9].

\section{ApproAch to Problem Resolution}

Recent introduced technology utilizes polymer-linkage specific enzymes complexes to hydrolyze polymers to non-damaging fragments. Such applications have been coupled with a follow-up treatment involving an acid wash to remove acid-soluble bridging agents [2,7,10-17]. Enzymes are polymers of amino acids with a high molecular weight. They are produced by living organisms and can act as catalysts to promote specific reactions, under relatively mild conditions of $\mathrm{pH}$ and temperature [16]. Furthermore, as a catalyst, the original structure of an enzyme is unchanged by the reaction it promotes; it can then initiate another, and so on.

The enzyme based catalytic activities are often extremely specific that is to say a certain enzyme can only catalyze the break down or synthesis of certain compounds. Different from acidic or oxidative processes, the enzyme systems will not react with substances other than the targeted polymers. Therefore, corrosion of tubular goods as well as iron-promoted sludging are also avoided using the technology of polymer bio-degradation. The enzyme system attacks the drill-in fluid filter-cake damage by degrading the polymer, which will ensure the free flow of CBM flowing into the wellbore.

\section{EXPERIMENTAL PROCEDURES}

\section{A. Experimental Materials}

Bio-degradable polymers included guar, carboxymethyl cellulose (CMC) and Konjak. Enzyme additives were enzymes SE-1, SE-2 and SE-3, which were the complex of protease, xylanase, amylase, $\beta$-glucanase, cellulose, et al. Bentonite and sodium carbonate were used to make polymer muds.

\section{B. Test Procedure 1: Rheological Model of Polymer Drilling Fluids}

Polymers such as guar, hydroxypropyl guar (HPG), 
hydroxyethyl cellulose (HEC) and Fenugreek gum were dispersed in water separately with the concentration of 0.5 weight percent $(\mathrm{wt} \%)$ where the viscometer was operated at $3000 \mathrm{rpm}$ and the mixing time was 30 minutes. ZNN six-speed rotary viscosimeter was used in the investigation of the rheological parameters of these polymer drilling fluids. Data Processing System (DPS) software was used to analyze the rheological models of polymer drilling fluids.

C. Test Procedure 2: Viscosity Reductions of Typical Bio-degradable Drilling fluids

Different enzymes were separately added into the single polymer drilling fluid, compound polymers drilling fluid and polymer mud and the apparent viscosity (AV), plastic viscosity (PV) and yield point (YP) of each formula were recorded with the change of time.

D. Test Procedure 3: Evaluation of the effects of different factors on the viscosity breaking behaviors of bio-degradable drilling fluids

Using apparent viscosity as the main evaluating parameter, laboratory tests were run to evaluate the effects of polymeric substrate type (single polymer, compound polymers and polymer mud), polymeric substrate concentration, enzyme type and enzyme concentration on the viscosity breaking behaviors of bio-degradable drilling fluids.

\section{RESUlts AND DisCUSSION}

\section{A. Rheological model of bio-degradable drilling fluids}

Table I stated the rheological parameters of several polymer drilling fluids and Fig. 1 showed that rheological curve of them. Taking the example of 0.5 $\mathrm{wt} \%$ guar drilling fluid, DPS software was utilized to analysis the rheological equations, determination coefficient $R^{2}, F$-value and $p$-value corresponding to different rheological model. The rheological equations and the parameters of regression analysis were displayed in Table II.

TABLE I RHEOLOGICAL PARAMETES OF POLYMER DRILLING FLUIDS

\begin{tabular}{|l|l|l|l|l|l|l|}
\hline Polymer & $\theta_{600}$ & $\theta_{300}$ & $\theta_{200}$ & $\theta_{100}$ & $\theta_{6}$ & $\theta_{3}$ \\
\hline guar & 46.5 & 36.1 & 31 & 28.8 & 9 & 6.7 \\
\hline HPG & 59.8 & 44 & 41.4 & 30 & 9.4 & 7 \\
\hline HEC & 45 & 25 & 22.1 & 14.6 & 3.8 & 3 \\
\hline Fenugreek gum & 47 & 34 & 28.2 & 22 & 6.8 & 5 \\
\hline
\end{tabular}

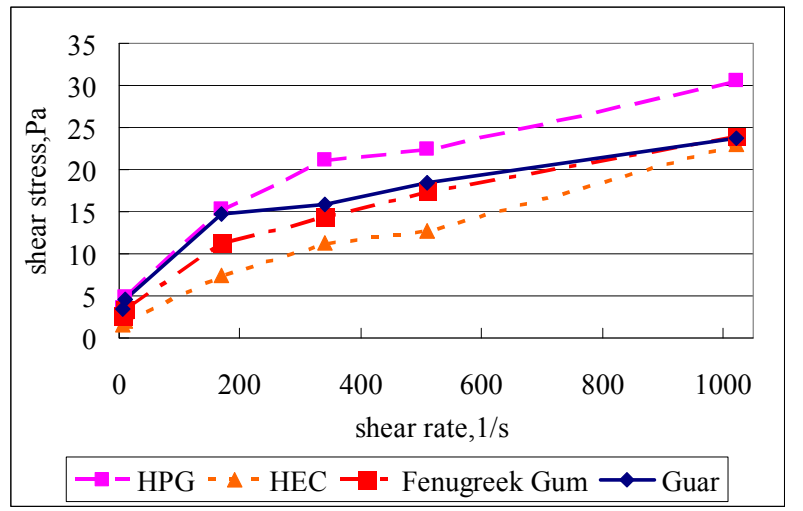

Fig.1 Rheological curve of typical polymer drilling fluids

It is generally acknowledged that the higher the determination coefficient $R^{2}$ and $F$-value or the lower the $p$-value, the equation has better regression performance. Based on an overall consideration of various factors, Power model had the best regression performance and it could be used to describe the rheological behaviors of $0.5 \mathrm{wt} \%$ guar drilling fluid.

With the same method, the rheological equations and the parameters of regression analysis of HPG drilling fluid, HEC drilling fluid and fenugreek gum drilling fluid were achieved and listed in Table III.

TABLE II RHEOLOGICAL EQUATIONS AND REGRESSION ANALYSIS PARAMETERS OF DIFFERENT RHEOLOGICAL MODELS (GUAR DRILLING FLUID)

\begin{tabular}{|l|l|l|l|l|}
\hline Rheological Model & Rheological Equation & $R^{2}$ & $F$ & $p$ \\
\hline Bingham Model & $\tau=7.030+0.019 \times \gamma$ & 0.8238 & 18.7076 & 0.0124 \\
\hline Power Model & $\tau=2.324 \times \gamma^{0.336}$ & 0.9876 & 318.8555 & 0.0001 \\
\hline Casson Model & $\tau^{1 / 2}=1.945+3.216 \times \gamma^{0.5} / 1000^{0.5}$ & 0.9232 & 48.0787 & 0.0023 \\
\hline Herschel-Bulkely Model & $\tau=3.912+4.886 \times \gamma^{0.248}$ & 0.9909 & 163.7724 & 0.0009 \\
\hline Robertson Stiff Model & $\tau=2.818(\gamma-3.469)^{0.306}$ & 0.9910 & 164.4238 & 0.0009 \\
\hline
\end{tabular}


TABLE III RHEOLOGICAL EQUATIONS AND REGRESSION ANALYSIS PARAMETERS OF OTHER POLYMERS DRILLING FLUID

\begin{tabular}{|l|l|l|l|l|}
\hline Polymer & Rheological Equation & $R^{2}$ & $F$ & $p$ \\
\hline HPG & $\tau=2.070 \times \gamma^{0.389}$ & 0.9957 & 935.2626 & 0 \\
\hline HEC & $\tau=0.263 \times \gamma^{0.641}$ & 0.9870 & 303.3164 & 0.0001 \\
\hline Fenugreek gum & $\tau=1.208 \times \gamma^{0.430}$ & 0.9988 & 3428.4056 & 0.0000 \\
\hline
\end{tabular}

Based on the results of Table 2 and Table 3, Power model was the optimal rheological model which could be utilized to describe the rheological behaviors of polymer drilling fluids [18].

\section{B. Viscosity Reductions of Typical Bio-degradable Drilling fluids}

\section{(1) Single polymer drilling fluid}

In Fig. 2, with the addition of enzyme SE-1, apparent viscosity of $0.5 \mathrm{wt} \%$ guar drilling fluid decreased from $23.5 \mathrm{mPa} \cdot \mathrm{s}$ to $5 \mathrm{mPa} \cdot \mathrm{s}$ in 48.5 hours. Plastic viscosity (PV) and yield point (YP) showed the similar characteristic in the degradation process.

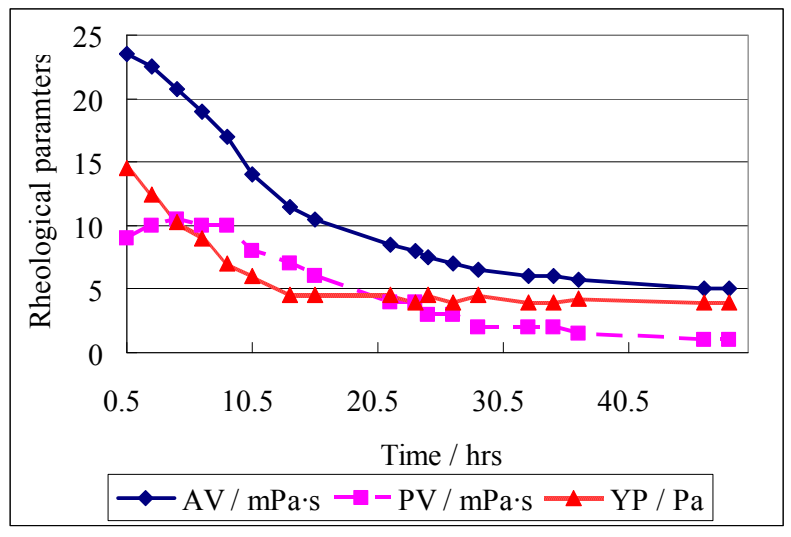

Fig.2 Viscosity reduction of guar drilling fluid

\section{(2) Compound polymers drilling fluid}

From Fig. 3 we can see that with the addition of enzyme SE-2, apparent viscosity of the compound drilling fluid of $0.3 \% \mathrm{CMC}$ plus $0.2 \mathrm{wt} \%$ guar declined from $25.5 \mathrm{mPa} \cdot \mathrm{s}$ to $5 \mathrm{mPa} \cdot \mathrm{s}$ in 46 hours. Plastic viscosity and yield point showed the homologous characteristic in the degradation process.

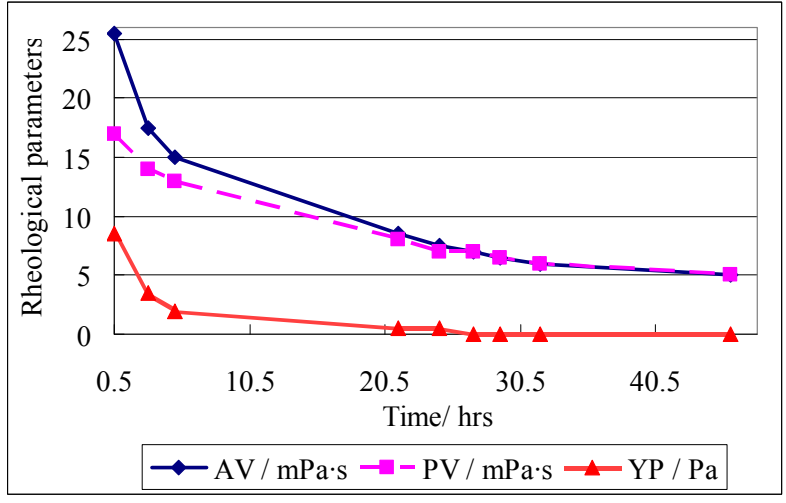

Fig.3 Viscosity reduction of compound polymers drilling fluid

\section{(3) Polymer mud}

Fig. 4 showed that in the initial process, the rheological curves showed slightly increase for the hydration of bentonite. With the addition of enzyme SE-2, apparent viscosity of this polymer mud could decrease from $15.5 \mathrm{mPa} \cdot \mathrm{s}$ to $5.5 \mathrm{mPa} \cdot \mathrm{s}$ in 46.5 hours. The plastic viscosity and yield point showed the similar behavior in the degradation process.

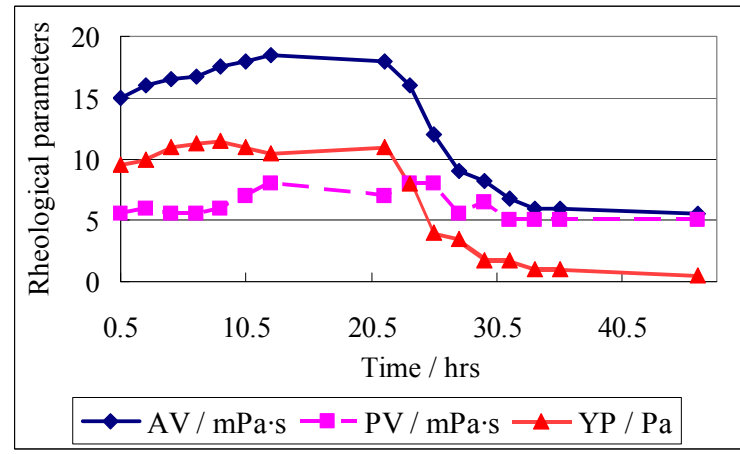

Fig.4 Viscosity reduction of polymer mud

C. Factors of the rheological behaviors of bio-degradable drilling fluids

\section{(1) Polymeric substrate type}

In room temperature $\left(25^{\circ} \mathrm{C}\right)$, with the same concentration of $0.5 \% \mathrm{wt} \%, \mathrm{CMC}$, guar and Konjak gum were mixed with $0.25 \mathrm{wt} \% \mathrm{SE}-1$ separately. The 
rheological parameters were recorded with the elapse of time, shown in Fig. 5. With the existence of enzyme SE-1, CMC, guar gum and konjak showed quite different degradation behavior.

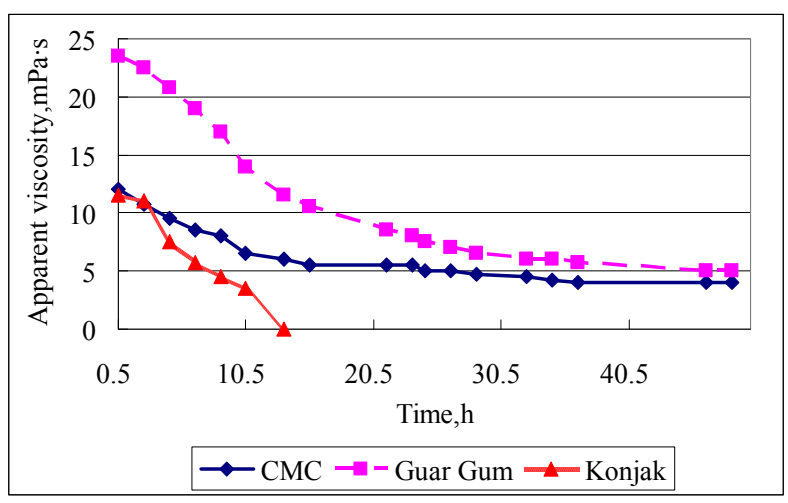

Fig. 5 Effect of substrate type on rheology of bio-degradable drilling

$$
\text { fluid }
$$

1) Guar gum's initial apparent viscosity was almost the double of the other two polymers for its high molecular weight $\left(1.127 \times 10^{6}\right)$.

2) Viscosity breaking time of Konjak was only 13.5 hours therefore it was easier to be degraded. It was fully degraded for its viscosity breaking ratio was $100 \%$.

3) Although the initial apparent viscosity of CMC solution and guar gum solution was different, they had very close final apparent viscosity. Therefore, it's not ridiculous that the viscosity breaking ratio of guar gum solution was $10 \%$ higher than CMC solution.

\section{(2) Polymeric substrate concentration}

In room temperature $\left(25^{\circ} \mathrm{C}\right), 0.5 \mathrm{wt} \% \mathrm{CMC}, 0.75 \mathrm{wt} \%$ $\mathrm{CMC}$ and $1 \mathrm{wt} \% \mathrm{CMC}$ were mixed with $0.25 \mathrm{wt} \% \mathrm{SE}-1$ separately. The rheological parameters were recorded with the change of time, shown in Fig. 6. With the elevated concentrations of $\mathrm{CMC}$, initial apparent viscosity increased from $12 \mathrm{mPa} \cdot \mathrm{s}$ to $36.75 \mathrm{mPa} \cdot \mathrm{s}$ and the final apparent viscosity performed the similar behavior. The viscosity breaking ratio of $0.75 \mathrm{wt} \% \mathrm{CMC}$ was almost $10 \%$ higher than that of $0.5 \mathrm{wt} \% \mathrm{CMC}$ while when the concentration increased to $1.0 \%$, the viscosity breaking ratio had a slight improve of $1.5 \%$. This means that the optimal proportion of CMC vs enzyme SE-1 was 3 to $1(0.75 \%$ divides by $0.25 \%)$.

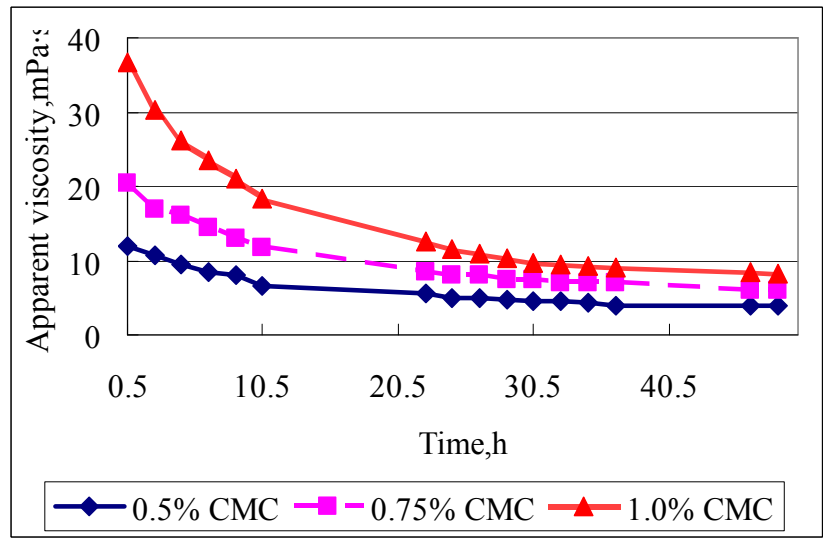

Fig. 6 Effect of substrate concentration on rheology of bio-degradable drilling fluid

\section{(3) Enzyme type}

In room temperature $\left(25^{\circ} \mathrm{C}\right), 0.25 \mathrm{wt} \%$ enzyme SE-1, $0.125 \mathrm{wt} \%$ enzyme SE-2 and $0.125 \mathrm{wt} \%$ enzyme SE-3 were added into $0.75 \mathrm{wt} \% \mathrm{CMC}$ drilling fluid. The rheological parameters were acquired with the change of time, listed in Fig. 7. We can conclude that three enzymes showed different viscosity breaking performance. The degradation process with enzyme SE-1 was moderate and the viscosity breaking ratio reached to $76 \%$ in 48.5 hours. Enzyme SE-2 immediately accelerated the degradation process in case it contacted with cellulose. The viscosity breaking ratio reached to $57 \%$ in only 30 minutes. While enzyme SE-3 had a rather slow degradation on $\mathrm{CMC}$ with the viscosity breaking ratio was only $20 \%$ in 73 hours. It could demonstrate that enzyme SE-3 had little effect on the degradation of CMC.

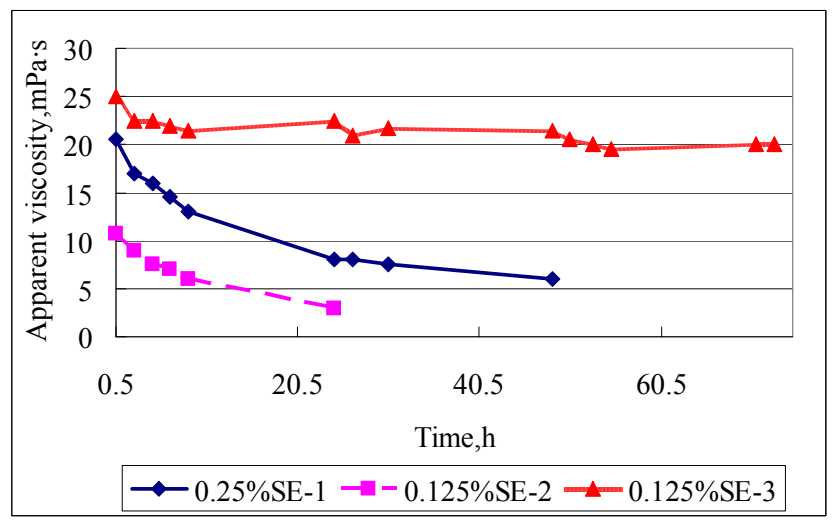

Fig. 7 Effect of bio-enzyme type on the rheology of bio-degradable drilling fluid

In room temperature $\left(25^{\circ} \mathrm{C}\right), 0.25 \mathrm{wt} \%$ enzyme $\mathrm{SE}-1$, 
$0.125 \mathrm{wt} \%$ enzyme SE-2 and $0.125 \mathrm{wt} \%$ SE-3 were added into $0.5 \mathrm{wt} \%$ guar drilling fluid. The rheological parameters were measured with the change of time, shown in Fig. 8. We can see that enzyme SE-2 showed strong reaction on guar, for the apparent viscosity decreased to $1 \mathrm{mPa} \cdot \mathrm{s}$ in only 10.5 hours. Furthermore, the viscosity breaking ratio reached to $72.34 \%$ in only 30 minutes. Enzymes SE-1 and SE-3 were more moderate, especially enzyme SE-3 showed better viscosity breaking performance when contacted with guar gum for the viscosity breaking ratio was $93.62 \%$ in 74.5 hours.

\section{(4) Enzyme concentration}

In the temperature of $50^{\circ} \mathrm{C}$, elevated concentrations of enzyme SE-2 were mixed with $0.6 \mathrm{wt} \%$ hydroxypropyl guar (HPG). The reaction was kept for 5 hours. The curve of viscosity breaking ratio varying with enzyme concentration was shown in Fig. 9. With the increased concentration of enzyme, the chance of a HPG molecular chain meeting with enzyme SE-2 would increase resulting in the increase of viscosity breaking ratio.

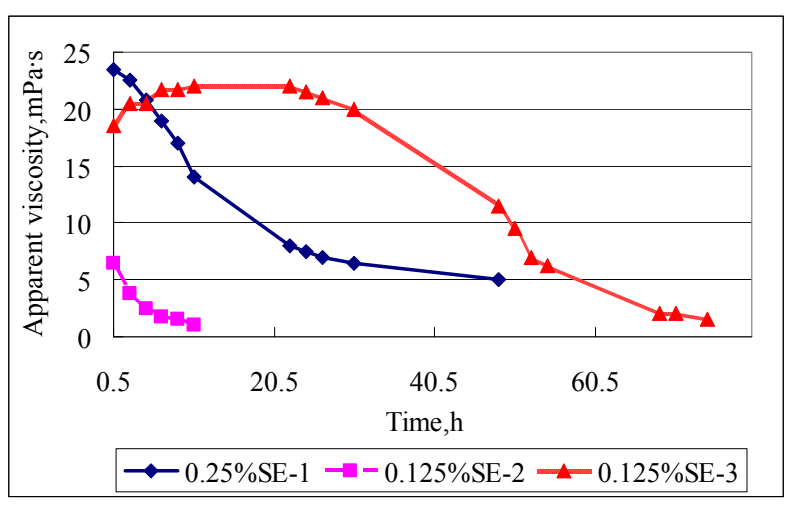

Fig. 8 Effect of bio-enzyme type on the rheology of bio-degradable drilling fluid

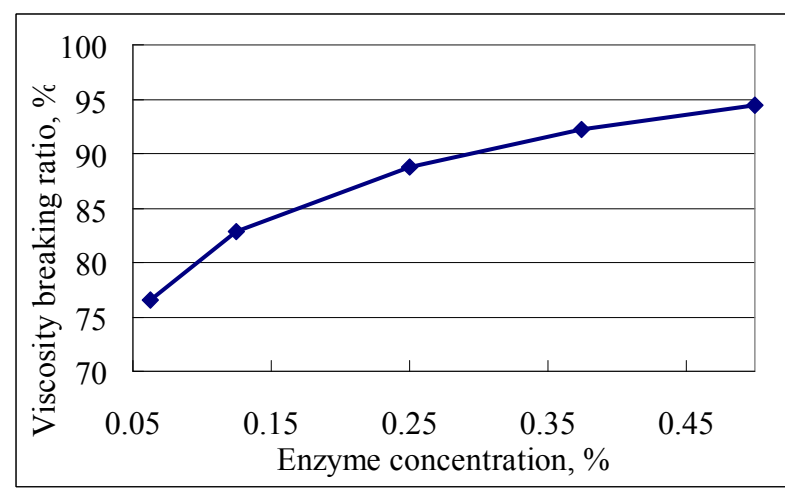

Fig. 9 Effect of enzyme concentration on the rheology of bio-degradable drilling fluid

\section{CONCLUSIONS}

The "clean" drill-in fluids can cause significant damage to the wellbore permeability in horizontal drilling of unconsolidated coal seam. Conventional oxidative solution or acid washes are often inadequate for removal of drill-in fluid filter-cake damage to achieve maximized well productivity. A newly developed polymer specific enzyme system, bio-degradable drilling fluid, for enhancing removal of drill-in fluid filter-cake damage has been developed and the rheological behaviors has been evaluated. Bio-degradable drilling fluid provides for specific polymeric damage removal without causing damage to the formation or tubular goods. Bio-degradable drilling fluid is environmentally friendly. Following conclusions could be acquired from above research.

(1) Power Law model was the optimal model to matching the rheological properties of bio-degradable drilling fluids;

(2) Compared with konjak, the degradations of $\mathrm{Na}-\mathrm{CMC}$ and guar gum were easier to be controlled;

(3) In the degradation of CMC by enzyme SE-1, the optimal weight concentration ratio of CMC to SE-1 was 3 to 1 ;

(4) Of the three enzymes, enzyme SE-2 had the highest activity and could be used to degrade polymer in shorter time;

(5) Higher enzyme concentration could speed up the degradation reaction;

(6) Viscosity breaking times fluctuating from 13.5 hours to 74.5 hours and viscosity breaking ratios varying from $20 \%$ to $100 \%$ could be achieved by modifying the formulations of BDFs;

Further study should focus on the lab experiments of the return of coal reservoir permeability and the field trial in horizontal drilling of unconsolidated coal seams.

\section{ACKNOWLEDGEMENT}

The authors wish to express our appreciation to Prof. $\mathrm{Wu}$ Xiaoming for his support of this endeavor. We also indebted to National Natural Science Foundation of China (NSFC) for the aid of projects "research on borehole and reservoir protecting mechanism of degradable drilling fluid in gas drainage borehole drilling 
of unconsolidated and soft coal seam” (No. 40802031) and "study on temporarily plugging mechanism of nano bridging materials in the drilling \& completion of low-porosity \& low-permeability coalbed methane reservior" (No. 41072111).

\section{REFERENCES}

[1] LeBlanc, Leonard, "Limiting, treating formation damage in horizontal, extended reach wells," Offshore, June 1996, pp.58.

[2] Brian B. Beall, Robert Tjon-Joe-Pin, and Harold D. Brannon, "Field experience validates effectiveness of drill-in fluid cleanup system," SPE 38570, 1997.

[3] McClarty, J.M., Dobson, J.W. and Dick, M.A, “Overview of offshore horizontal drilling/completion properties in unconsolidated sand stones in the Gulf of Mexico," OTC 7352, 1993.

[4] Len V. Baltoiu, Brent K. Warren, Thanos A. Natras, "State-of-the-Art in Coalbed Methane Drilling Fluids," SPE Drilling \& Completion, 2008, 23(3), pp. 250-257.

[5] K. Barr, "A guideline to optimize drilling fluids for coalbed methane reservoirs", SPE 123175, 2009.

[6] Lai Xiaoqing, Lou Yishan, Qu Yuanzhi, et al, "State-of-the-art \& development clue in drilling fluid technologies of coalbed methane exploitation in China," Journal of Oil and Gas Technology (Journal of Jianghan Petroleum Institue), 2009, 31(5), pp. 326-328.

[7] Beall, B.B., Brannon, H.D., TjonJoePin, R.M., O'Driscoll, $\mathrm{K}$, "Evaluation of a new technique for removing horizontal wellbore damage attributable to drill-in filter cake,” SPE $36429,1996$.

[8] R.M. Hodge, B.G. Augustine, R.C. Burton, W.W. Sanders, Donna Atkinson, "Evaluation and selection of drill-in-fluid candidates to minimize formation damage," SPE Drilling \& Completion, 1997, 12(3): pp.174-179.

[9] Burnett, D.B, “Using a physical wellbore model to study formation damage problems in well completions," SPE 27393, 1994.

[10] Tjon-Joe-Pin, Robert, Brannon, H.D., Rickards, A. R., "Remedial treatment for polymeric damage removal provides improved well productivity,” SPE 25214, 1993.

[11] A. R. Rickards, R. M. Tjon-Joe-Pin, and J. L. Boles, "Enzymatic breaker system for non-damaging removal of cellulose-based blocking gels," SPE 25488,1993.
[12] H.D. Brannon, R. M. Tjon-Joe-Pin, "Biotechnological breakthrough improves performance of moderate to high-temperature fracturing applications," SPE 28513, 1994.

[13] H.D. Brannon, R. M. Tjon-Joe-Pin, "Application of damage removal treatment results in multi-fold well productivity improvement: a case study,” SPE 29677, 1995.

[14] TjonJoePin, R.M.,et al, "Method of dissolving organic filter cake obtained from polysaccharide based fluids used in production operations and completions of oil and gas wells," U.S. Patent No 5,247,995(1993).

[15] K.P. O’Driscoll, N.M. Amin, I.Y. Tantawi, “New treatment for removal of mud-polymer damage in multilateral wells drilled using starch-based fluids," SPE Drilling \& Completion, 15(3), 2000, 167-176.

[16] Harris, R.E., McKay, I.D., "New applications for enzymes in oil and gas production," SPE 50621, 1998.

[17] Cai Ji-hua, Gu Sui, Liu Hao, "Experimental study on bio-degradable drilling fluid in Gas extracting drilling of unconsolidated and soft coal seam", Progress in Safety Science and Technology, Vol.VIII, 2010, pp. 1463-1469.

[18] Cai Jihua, Liu Hao, Gu Sui, "Empirical correlation to predict viscosity breaking ratio of guar-based biodegradable drilling fluid, " ICIECS 2010, pp. 5-8.

Cai Jihua was born in December $1^{\text {st }}, 1978$ in Hubei, China. Cai got a Master degree of geological engineering in 2003 and a Ph.D degree of geological engineering in 2006, both in China University of Geosciences (CUG). Cai worked as a postdoctoral of petroleum engineering in University of Texas at Austin (UT Austin), USA, between September 2009 and August 2010.

$\mathrm{He}$ is currently an associate professor at CUG and has published over 20 journal articles and conference papers in the field of core drilling, petroleum engineering, trenchless technology et al, either in Chinese or in English. Now his research interests include drilling fluid and reservoir protection.

Dr. Cai is now a member of Society of Petroleum Engineers (SPE). 